Denis W. F. De Souza, ; VARGAS, A.N. ; João Bosco Ribeiro do Val ; FREITAS, A. M. ; LORINI, I. . Control of temperature to suppress the population of Rhyzopertha dominica (F.) (Coleoptera, Bostrichidae) in a grain silo prototype. In: European Control Conference ECC 2013, 2013, Zurich. Proc. European Control Conference 2013, 2013. p. 4089-4093.

\title{
Control of temperature to suppress the population of Rhyzopertha dominica (F.) (Coleoptera, Bostrichidae) in a grain silo prototype
}

\author{
Denis W. F. De Souza, Alessandro N. Vargas, João B. R. do Val, Adriana M. Freitas, and Irineu Lorini
}

\begin{abstract}
This note presents some results from laboratory experiments that were conducted to characterize the influence of temperature in the mortality of adults of the insect known as lesser grain borer, Rhyzopertha dominica (F.). The insects were separated into strains and were appropriately immersed into a mass of wheat, and the infested wheat was stored in a silo bin of small dimensions with control of temperature. Our experiments indicates that the control of temperature can be used as a successful tool to increase the mortality of $R$. dominica in grain silos. The paper also describes the construction of the electrical device that implements the control of temperature in the proposed grain silo prototype.
\end{abstract}

\section{INTRODUCTION}

The quality of the grains produced and stored for human consumption demands the highest level of concerns from the governments and society [1]. Unfortunately, an expressive amount of these grains are lost due to lack of quality caused by the proliferation of insect pests. To take an account, the Brazilian government estimates a grain harvest of 165.8 million t at the 2012 season, and $10 \%$ of it may become inadequate for consumption due to the action of insects [2].

It is clear that the damage caused by insects deteriorates the quality of the grains, and to control pests farmers and storage managers have to use different methods to reduce pest infestation in bins. The most common strategy to control the pest is to use pesticide directly

Research supported in part by Brazilian agencies FAPESP Grants 03/06736-7 and 04/06947-0; CNPq Grants 304856/20070 and 471557/2009-9; Brazilian private company PID BRASIL Automação Industrial Ltda; Spanish agency Fundación Carolina Programa "Movilidad de profesores e investigadores Brasil-España. C.2010"; and Spanish research center Basque Center for Applied Mathematics - "BCAM - Visiting Fellow Program"

Denis W. F. De Souza is with PID BRASIL Automação Industrial Ltda, Av. Arthur Thomas, 902, 86065-000 Londrina-PR, Brazil. E-mail: denis@pidbrasil.com.br

Alessandro N. Vargas is with Universidade Tecnológica Federal do Paraná, UTFPR, Av. Alberto Carazzai 1640, 86300-000 Cornelio Procópio-PR, Brazil, and with Basque Center for Applied Mathematics, BCAM, Alameda de Mazarredo 14, E-48009 Bilbao, Vizcaya, Spain. E-mail: avargas@utfpr.edu.br

João B. R. do Val is with Universidade Estadual de Campinas, UNICAMP, Fac. de Engenharia Elétrica e de Computação, Depto. de Telemática, C.P. 6101, 13081-970 Campinas-SP, Brazil. E-mail:jbosco@dt.fee.unicamp.br

Adriana M. Freitas and Irineu Lorini are with Empresa Brasileira de Pesquisa Agropecuária, Embrapa Soja, Rod. Carlos João Strass - Distrito de Warta 86001-970 - LondrinaPR, Brazil. E-mail:adrianamarques@cnpso.embrapa.br; lorini@cnpso.embrapa.br on the grains [2], [3], [4], [5], [6]. However, it is known that pesticide residues may cause health problems [7]. Moreover, in many cases the use of pesticide fails to control the infestation, see the example of the lesser grain borer Rhyzopertha dominica (F.) (Coleoptera, Bostrichidae) (Fig. 1), the most important pest of stored wheat in Brazil, which exhibits a strong resistence to phosphine [2], [5]. An alternative method to the use of pesticide is now described.

Many investigators suggest that an efficient strategy for controlling the infestation of $R$. dominica is to heat the mass of grains during a certain period of time [8], [9], [10], [11]. This technique has clear advantages when compared with the other ones based on pesticides, specially because the former does not generate toxic residues. This paper corroborates with such findings, as we detail next.

The main contribution of this paper is twofold. First, it presents the apparatus used to construct a grain silo prototype with control of temperature. The silo prototype has small dimensions and is capable to reproduce in a laboratory environment the behavior of many industrial silos. The second contribution is to describe the experiments that were taken to evaluate the disinfestation property of the silo prototype. The idea was to use the silo bin to store wheat infested with $R$. dominica, and by exposing the wheat to a control of temperature we were able to determine the mortality assessment of $R$. dominica.

The experimental outcome indicates that the control of temperature can be used positively as an efficient tool to diminish the population of $R$. dominica in a mass of wheat, and in particular a complete suppression of the insects can be attained when the controlled temperature is made higher.

These experimental facts confirm the heat, and consequently the control of temperature, as a feasible tool to disinfest contaminated wheat when stored in silo bins.

\section{Control of temperature: MAterials AND METHODS}

This section describes the materials and methods used in the construction of the grain silo prototype, and the electrical apparatus developed to implement the control of temperature therein.

\section{A. Grain silo prototype}

The main structure of the grain silo prototype is made by galvanized steel, in a cylindrical format, having a 
Denis W. F. De Souza, ; VARGAS, A.N. ; João Bosco Ribeiro do Val ; FREITAS, A. M. ; LORINI, I. . Control of temperature to suppress the population of Rhyzopertha dominica (F.) (Coleoptera, Bostrichidae) in a grain silo prototype. In: European Control Conference ECC 2013, 2013, Zurich. Proc. European Control Conference 2013. 2013. D. 4089-4093.

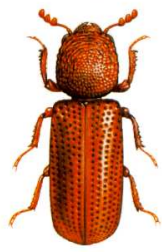

Fig. 1. Pictorial illustration of Rhyzopertha dominica (F.) (Coleoptera, Bostrichidae). Image: Courtesy of the National Soybean Research Centre (Embrapa Soybean), Brazil.

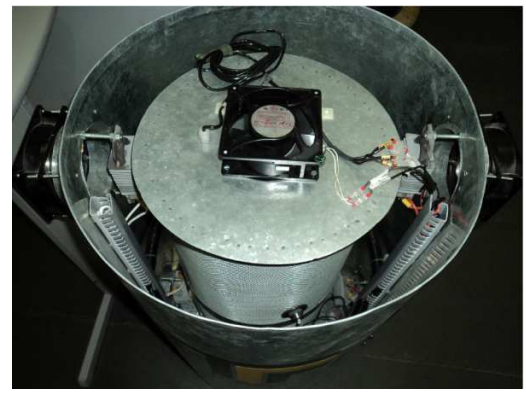

Fig. 2. A view from the top of the grain silo prototype (picture taken without the roof).

cylindrical inner bin to store the grains (Fig. 2). The wall of the inner cylindrical shell is constructed with a metal screen mesh to facilitate the air flow. The external prototype has dimensions of $750 \mathrm{~mm}$ in height and 400 $\mathrm{mm}$ in base diameter. The inner bin has dimensions of $680 \mathrm{~mm}$ in height and $300 \mathrm{~mm}$ in base diameter, which represents the quantity 48 of cubic decimeter of grains as a installed storage capacity. In the practical experiments, $40 \mathrm{Kg}$ of wheat was comfortably accommodated in its structure.

A ventilating system was used to induce an uniform gradient of temperature within the grain silo prototype (Fig. 3). Namely, three fans draw the cold air from the exterior environment and force its passage through the heating resistences. The warmer air enters into the inner bin to act on the grains stored therein, and a fan attached in the top of the inner bin pushes warm air up. Besides, other fan makes the overall aeration of the main structure (see [12] for an account on the importance of aeration). Three resistors of 1200 Watts each was used to heat the air inside the bin (Fig. 3).

\section{B. Electrical control panel and supervisory software}

The electrical control panel implements the control of temperature inside the grain silo prototype (Fig. 4).

The control strategy is in the usual output feedback form with two independent feedback links corresponding to the two temperature measurements. Namely, there are two temperature measurement devices based on thermocouples (code PT100) that generate signals to be processed by the two corresponding controllers; in

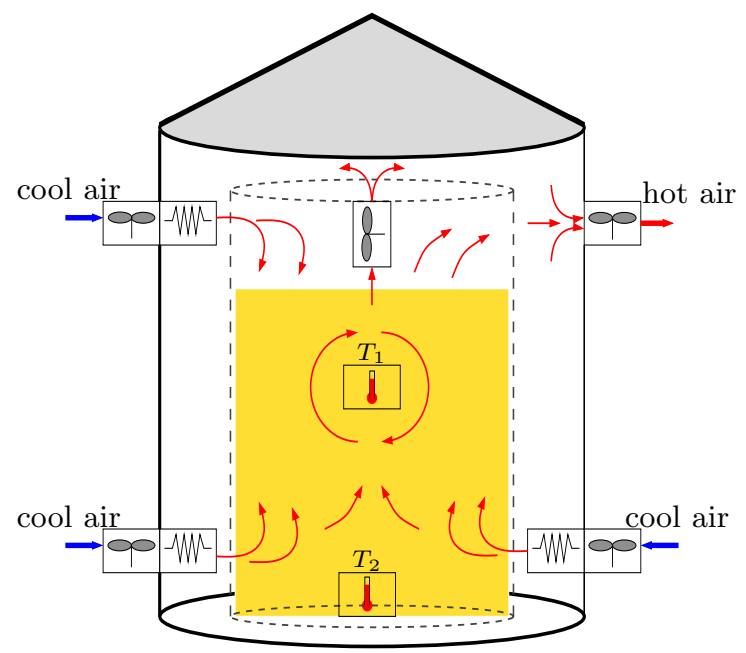

Fig. 3. The illustration presents how the control of temperature is implemented inside the grain silo structure. The cold air flow is drained through three distinct orifices and crosses the corresponding heating resistences. The hot air then acts on the wheat kernels stored in the inner bin, as indicated by the arrows, changing their temperature. The sensors $T_{1}$ and $T_{2}$ measures the instantaneous temperature from the beans and the controllers interpret this information to regulate appropriately the energy sent to the heat resistences. An orifice is dedicated to discard spurious impurities and hot air.

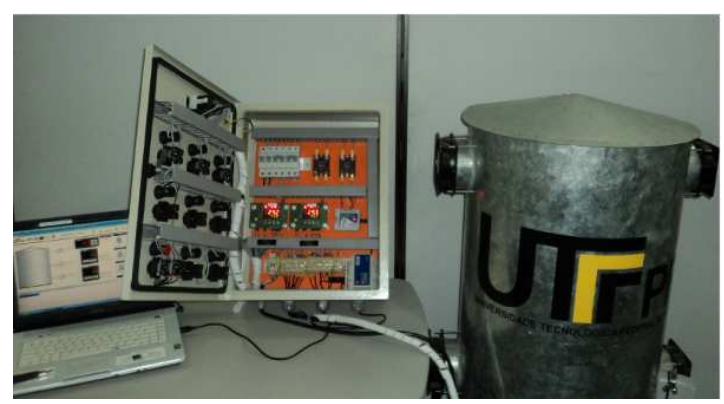

Fig. 4. Picture of the laboratory testbed used in the experiments. The apparatus comprises the grain silo prototype that stored wheat infested by $R$. dominica, the electrical control panel that implements the control of temperature inside the silo, and a computer to collect and save all of the required data.

our setup we have used two Novus $\mathrm{N}_{12} 0^{1}$ industrial controllers. The controllers implement the Proportional Integrative Derivative (PID) strategy [13].

It is important to emphasize that the two temperature measurements are taken in different locations of the mass of grains, and the respective controllers actuate to generate the necessary heat from the corresponding resistors (Fig. 3).

The panel has solid-state relays to load the heat resistors and a hardkey to ininialize the communication between the electrical control panel and a computer

\footnotetext{
$1_{\text {www . novusautomation. com }}$
} 
Denis W. F. De Souza, ; VARGAS, A.N. ; João Bosco Ribeiro do Val ; FREITAS, A. M. ; LORINI, I. . Control of temperature to suppress the population of Rhyzopertha dominica (F.) (Coleoptera, Bostrichidae) in a grain silo prototype. In: European Control Conference ECC 2013, 2013, Zurich. Proc. European Control Conference 2013. 2013 n. 4089-4093.

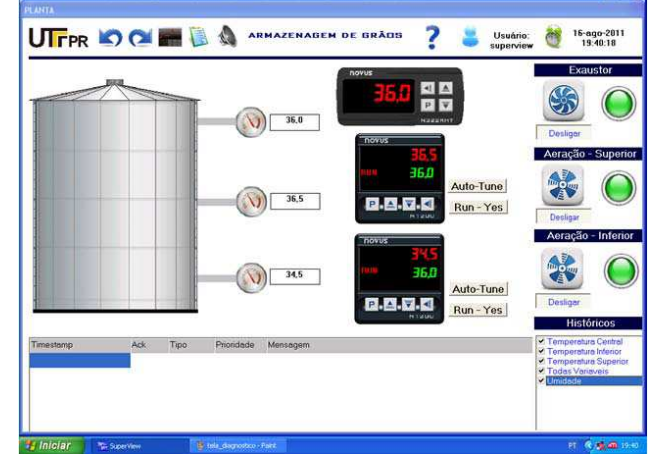

Fig. 5. Supervisory software screen. The software collects and saves all of the data generated by the electrical control panel during the control of temperature.

whenever necessary. In fact, a supervisory software was developed to monitore and store in the computer all the data generated by the electrical control panel (Fig. 5). Notice that the electrical control panel keeps the control of temperature in the bin even if the supervisory software is off.

\section{Feedback control system}

The involved thermal process of controlling the temperature inside the grain silo prototype is a two-input two-output control system. In fact, the plant has two independent reference inputs and two measured temperature outputs, and each control loop has its own PID controller.

The measured temperatures on the sensors are identified as $T_{1}$ e $T_{2}$, and the geometric displacement of them are shown in Fig. 3.

The two PID controllers we used in this project work independently from each other to actuate in the heat resistors inside the silo, although the heating effects of both jointly influence the temperature on the two sensors. In addition, the fans produce an air flow inside the bin, and these combined with the heat resistors impose hard nonlinearities on the system. The investigation on the nonlinear model of the silo is not in the scope of this paper.

To tune the parameters of the two PID controllers, we took both reference inputs at the same level and followed the tunning strategy as suggested by the Ziegler-Nichols method [13, Ch. 4.3].

\section{EXPERIMENTS WITH INSECTS: MATERIALS AND METHODS}

This section describes the material and methods we used in the experiments with $R$. dominica.

\section{A. Insects and treatments}

The $R$. dominica samples were taken from a colony that has been maintained at National Soybean Research Centre (Embrapa Soybean), Londrina, Paraná, Brazil.
Forty-five jars with two hundred adults insects of R. dominica each were reared in wheat grain at the laboratory for forty days to be used in the experiments. After forty days rearing the insects and wheat grain of each jar were deposited into a small chamber sealed across the top and bottom with filter paper, and delivered in the prototype silo according the experiment temperature regime.

A number of nine experiments were carried out, and all of them followed the next routine. We picked out four jars and they were placed in the silo bin fulfilled by wheat, in such a way that the jars were stacked on top of one another with distance of $15 \mathrm{~cm}$ between one from another. This distance was also observed from the last jar and the ground of the bin.

The wheat grains inside the bin were exposed to the control of temperature at $35^{\circ} \mathrm{C}$ for 24 hours. During this period, other jar served as the control treatment and was maintained outside the silo under restricted conditions $\left(25 \pm 1^{\circ} \mathrm{C}\right.$ and $65 \pm 5 \%$ relative humidity). After 24 hours, all of the jars were substituted by other five fresh ones, and the process was then repetead for 72 hours, and similarly for 120 hours.

The procedure restarted with temperatures at $47.5^{\circ} \mathrm{C}$, and a new one at $60^{\circ} \mathrm{C}$, for both maintaining the period of evaluation (24, 72, and 120 hours). Notice that nine experiments were carried out and forty-five jars were used on them.

After completing every stage of the experiment, the contents of the jars were took off and the grains were sieved to separate and count the number of dead and alive adults of $R$. dominica. The resulting values were then recorded and used for statistic analysis as ANOVA and the means discriminated by Tukey test $[14$, p. 256] using SASM-Agri software [15].

\section{Results AND Discussion}

The experimental process of controlling the temperature of the infested wheat, stored in the grain silo prototype, was run in the laboratory testbed. Two sensors $T_{1}$ and $T_{2}$, located in the bottom and middle of the inner bin, respectively, measured the temperatures, and for sake of illustration we present the generated data corresponding to the references at $35^{\circ} \mathrm{C}, 47.5^{\circ} \mathrm{C}$, and $60^{\circ} \mathrm{C}$ for 120 hours (Fig. 6). The figure suggests an periodic oscillation of the temperature of the wheat and this oscillation tends to be maintained as the time evolves, a fact that indicates that the control process is second moment stable [16].

The insects mortality were $100 \%$ for temperatures of $47.5^{\circ} \mathrm{C}$ and $60^{\circ} \mathrm{C}$ in all exposure time as 24,72 , and 120 hours (Table 1 ) showing that the temperature affects the adult mortality of $R$. dominica. The low temperature as $35^{\circ} \mathrm{C}$ proved not cause any mortality of adult insects being statistically similar of control experiment.

In conclusion, the control of temperature for the grain silo prototype was implemented by using heat drawn from electricity. For industrial silos, there are other 
Denis W. F. De Souza, ; VARGAS, A.N. ; João Bosco Ribeiro do Val ; FREITAS, A. M. ; LORINI, I. . Control of temperature to suppress the population of Rhyzopertha dominica (F.) (Coleoptera, Bostrichidae) in a grain silo prototype. In: European Control Conference ECC 2013, 2013, Zurich. Proc. Euronean Control Conference 2013. 2013. n. 4089-4093.
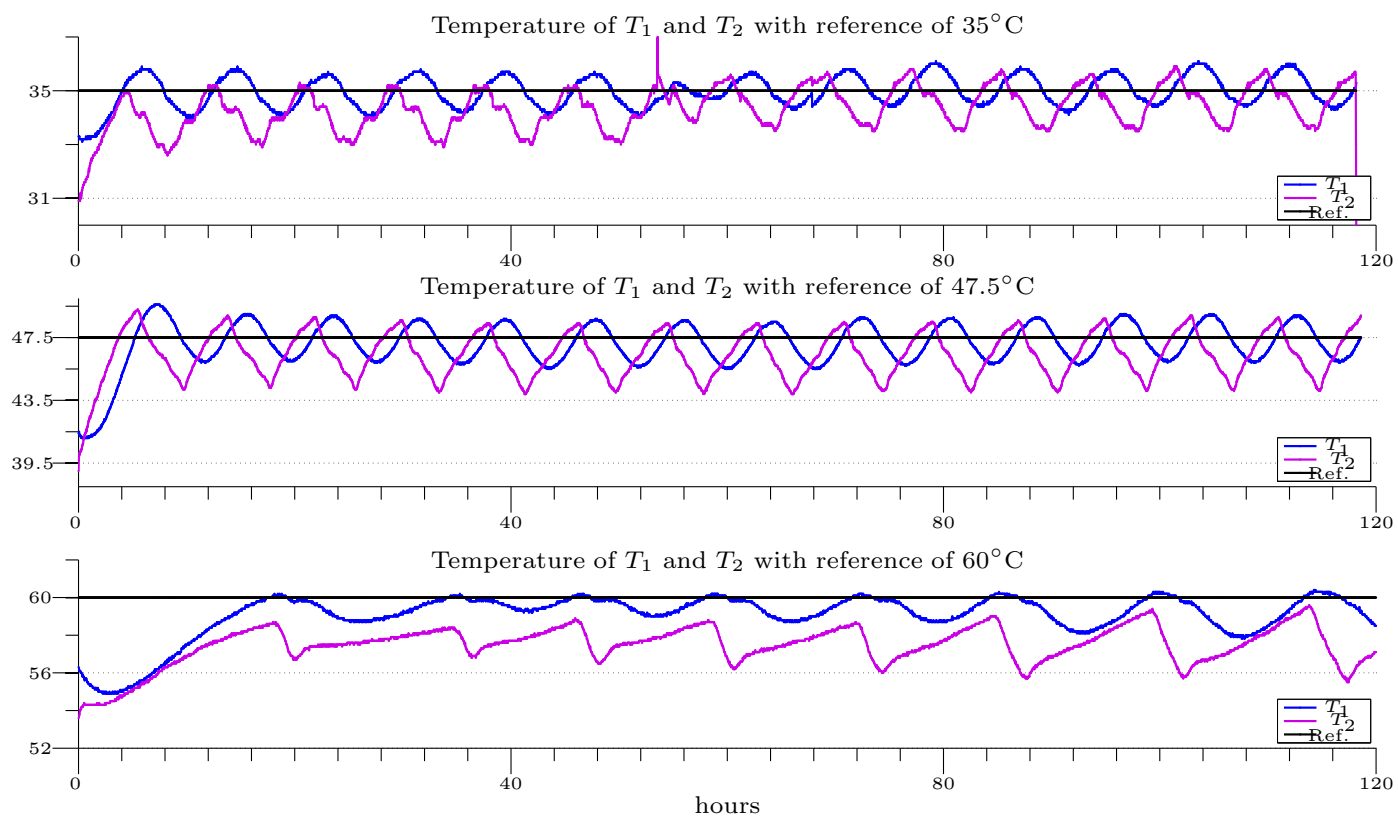

Fig. 6. Temperature of the wheat measured by the sensors located in the bottom and middle of the inner bin. The temperature references are $35^{\circ} \mathrm{C}, 47.5^{\circ} \mathrm{C}$, and $60^{\circ} \mathrm{C}$, corresponding to the figures from top to down.

options of heat generators with a favorable cost per $\mathrm{t}$ for wheat [8, Fig.7]. This reasoning, associated with the positive benefits demonstrated by our experimental approach, allows us to believe that the control of temperature can be used as a successful tool for disinfestation of industrial grain silos. Although the grain quality of wheat

TABLE I

Statistical mean number of Dead and alive adults of $R$. dominica CORRESPONDING TO DIFFERENT TEMPERATURES AND EXPOSITION TIMES DRAWN FROM A SILO WITH WHEAT AND CONTROLLED TEMPERATURE.

\begin{tabular}{ccrr}
\hline Temperature & Exposition & Dead adults $^{1}$ & Alive adults $^{1}$ \\
\hline \multirow{3}{*}{$35^{\circ} \mathrm{C}$} & $24 \mathrm{~h}$ & $7.25 \mathrm{~d}$ & $161.00 \mathrm{a}$ \\
& $72 \mathrm{~h}$ & $42.25 \mathrm{~b}$ & $133.25 \mathrm{a}$ \\
& $120 \mathrm{~h}$ & $22.75 \mathrm{bc}$ & $137.75 \mathrm{a}$ \\
\hline \multirow{3}{*}{$47.5^{\circ} \mathrm{C}$} & $24 \mathrm{~h}$ & $191.50 \mathrm{a}$ & $7.50 \mathrm{~b}$ \\
& $72 \mathrm{~h}$ & $200 \mathrm{a}$ & $0 \mathrm{~b}$ \\
& $120 \mathrm{~h}$ & $200 \mathrm{a}$ & $0 \mathrm{~b}$ \\
\hline \multirow{3}{*}{$60^{\circ} \mathrm{C}$} & $24 \mathrm{~h}$ & $200 \mathrm{a}$ & $0 \mathrm{~b}$ \\
& $72 \mathrm{~h}$ & $200 \mathrm{a}$ & $0 \mathrm{~b}$ \\
& $120 \mathrm{~h}$ & $200 \mathrm{a}$ & $0 \mathrm{~b}$ \\
\hline & Reference & $13.22 \mathrm{~cd}$ & $157.11 \mathrm{a}$ \\
& C.V. $(\%)^{3}$ & 6.88 & 13.88 \\
\hline
\end{tabular}

Means followed by the same letter, within the same column, are not significantly different at the 0.05 level using Tukey's test.

${ }^{1}$ Each strain contained 200 alive insects before the start of the experiment. ${ }^{2}$ Reference control group. ${ }^{3}$ C.V. stands for coefficient of variation. was not analyzed and it can be influenced negatively by the high temperature, a future experiment is needed recording the industrial analysis of wheat before and after temperature exposition.

\section{REFERENCES}

[1] P. A. A. Pereira, G. B. Martha, C. A. M. Santana, and E. Alves, "The development of Brazilian agriculture: future technological challenges and opportunities," Agriculture \&6 Food Security, vol. 1, no. 4, pp. 1-12, 2012.

[2] I. Lorini and D. J. Galley, "Deltamethrin resistance in Rhyzopertha dominica (F.) (Coleoptera: Bostrichidae), a pest of stored grain in Brazil," Journal of Stored Products Research, vol. 35, no. 1, pp. 37-45, 1999.

[3] P. A. Edde, "A review of the biology and control of Rhyzopertha dominica (F.) the lesser grain borer," Journal of Stored Products Research, vol. 48, pp. 1-18, 2012.

[4] I. Lorini and D. J. Galley, "Estimation of realized heritability of resistance to deltamethrin insecticide in selected strains of Rhyzopertha Dominica (F.) (Coleopetra: Bostrychidae)," Journal of Stored Products Research, vol. 36, no. 2, pp. 119124, 2000.

[5] I. Lorini, P. J. Collins, G. J. Daglish, M. K. Nayak, and H. Pavic, "Detection and characterisation of strong resistance to phosphine in Brazilian Rhyzopertha dominica (F.) (Coleoptera: Bostrychidae)," Pest Management Science, vol. 63, pp. 358-364, 2007.

[6] M. Shi, P. J. Collins, J. Ridsdill-Smith, and M. Renton, "Individual-based modelling of the efficacy of fumigation tactics to control lesser grain borer (Rhyzopertha dominica) in stored grain," Journal of Stored Products Research, vol. 51, no. 4, pp. 23-32, 2012.

[7] G. Kaushik, S. Satya, and S. N. Naik, "Food processing a tool to pesticide residue dissipation - A review," Food Research International, vol. 42 , no. 1 , pp. 26-40, 2009.

[8] S. J. Beckett and R. Morton, "Mortality of Rhyzopertha dominica (F.) (Coleoptera: Bostrychidae) at grain temperatures ranging from $50^{\circ} \mathrm{C}$ to $60^{\circ} \mathrm{C}$ obtained at different rates of heating in a spouted bed," Journal of Stored Products Research, vol. 39, no. 3, pp. 313-332, 2003. 
Denis W. F. De Souza, ; VARGAS, A.N. ; João Bosco Ribeiro do Val ; FREITAS, A. M. ; LORINI, I. . Control of temperature to suppress the population of Rhyzopertha dominica (F.) (Coleoptera, Bostrichidae) in a grain silo prototype. In: European Control Conference ECC 2013, 2013, Zurich. Proc. European Control Conference 2013, 2013. p. 4089-4093.

[9] S. J. Beckett, R. Morton, and J. A. Darby, "The mortality of Rhyzopertha dominica (F.) (Coleoptera: Bostrychidae) and Sitophilus oryzae (L.) (Coleoptera: Curculionidae) at moderate temperatures," Journal of Stored Products Research, vol. 34, no. 4, pp. 363-376, 1998.

[10] P. W. Flinn and D. W. Hagstrum, "Movement of Rhyzopertha dominica in response to temperature gradients in stored wheat," Journal of Stored Products Research, vol. 47, no. 4, pp. 407-410, 2011.

[11] M. Khamis, B. Subramanyam, P. W. Flinn, H. Dogan, A. Jager, and J. A. Gwirtz, "Susceptibility of various life stages of Rhyzopertha dominica (Coleoptera: Bostrichidae) to flameless catalytic infrared radiation," Journal of Economic Entomology, vol. 103, no. 4, pp. 1508-1516, 2010.

[12] G. R. Thorpe, "Modelling ecosystems in ventilated conical

bottomed farm grain silos," Ecological Modelling, vol. 94, no. 2-3, pp. 255-286, 1997.

[13] K. J. Åström and T. Hägglund, PID controllers: Theory, design and tuning. Research Triangle Park, N.C. Instrument Society of America, 1995.

[14] R. J. Freund and W. J. Wilson, Statistical Methods, 2nd ed. San Diego, CA, USA: Academic Press, 2003.

[15] M. G. Canteri, R. A. Althaus, J. S. Virgens Filho, E. A. Giglioti, and C. V. Godoy, "SASM - Agri: Sistema para análise e separação de médias em experimentos agrícolas pelos métodos scoft-knott, tukey e duncan," Revista Brasileira de Agrocomputação, vol. 1, pp. 18-24, 2001.

[16] A. N. Vargas and J. B. R. do Val, "Average cost and stability of time-varying linear systems," IEEE Trans. Automat. Control, vol. 55, pp. $714-720,2010$. 